\title{
Research Article \\ Cardio respiratory fitness in children with developmental coordination disorder
}

\author{
Sujatha, B. ${ }^{1}$, Jagatheesan Alagesan ${ }^{2}$, Priyanga Seemathan ${ }^{3}$, Sangeetha Sadhasivam ${ }^{3}$ \\ ${ }^{1} \mathrm{PhD}$ Scholar, ${ }^{2}$ Professor, ${ }^{3} \mathrm{BPT}$ Graduate, Saveetha College of Physiotherapy, SIMATS, Saveetha nagar Thandalam, Chennai \\ 602105, Tamil Nadu, India
}

(Received: May $2020 \quad$ Revised: October $2020 \quad$ Accepted: November 2020)

Corresponding author: Jagatheesan Alagesan. Email: priyaseemathan@ gmail.com

\begin{abstract}
Introduction and Aim: Developmental Coordination Disorder (DCD) is a neurodevelopmental condition in children, with motor coordination disabilities. Children with DCD not only exhibit poor motor coordination, but also experience poor performance in physical activities and are found to have poor physical fitness. The purpose of this study is to evaluate the cardio respiratory fitness in children with developmental coordination disorder.
\end{abstract}

Materials and Methods: The materials used for the study were DCDQ'07 questionnaire, (Bruinink's- Oseretsky Test-ed 2) BOT2 tool, (Diagnostic and Statistical Manual of Mental Disorders, ed-5) DSM-V diagnostic criteria, cones, 2 wooden blocks, measuring tape, stop watch. Twenty-six individuals were selected based on the inclusion and exclusion criteria out of which only 24 children participated in the study. DCD children were screened using DCDQ'07questionnaire, BOT2 tool, DSM-V diagnostic criteria and the cardio respiratory fitness is evaluated using $20 \mathrm{~m}$ shuttle run test. Comparison of Cardio respiratory fitness was done between the children with DCD and children without DCD.

Results: The results were determined by statistical analysis, following $20 \mathrm{~m}$ shuttle run test. Our findings indicate, cardio-respiratory fitness in children with DCD was significantly less than their peers of same age without DCD and are more likely to be in a high-risk group.

Conclusion: The current study supports lower cardio vascular fitness in children with DCD when compared to children without DCD, moreover no study has so far compared the Cardio respiratory fitness among DCD children and their normal peers.

Keywords: Developmental coordination disorder; cardio respiratory fitness; 20m shuttle run test; DCD’07 questionnaire

\section{INTRODUCTION}

$\mathrm{D}$ evelopmental coordination disorder is a neurodevelopmental disorder that affects the habit of learning and developing a skill and the activities that include fine and gross motor coordination that is required for the expected age limit (1). 5-6\% of the school aged children are affected by DCD approximately and researchers believe that it is due to delayed development of brain, though researches and literatures are available none could prove the primary cause of DCD. Developmental coordination disorder is formally recognised as a lifelong condition by world health organisation and some international organisations. Due to this disorder, speech of the child may be affected and some social participation like academic activities, interaction with the society, playing activities may be decreased (2). This disorder also causes delayed functional activities that are required normally for the child at the respected age like sitting to standing, walking, jumping, building blocks, drawing and other activities such as performing certain tasks like tying the shoe lace, using knife and fork and school activities participation. Coordination problems are caused because of flaccidity and weakness of muscle (3). The child with DCD even without any neuromuscular disorders or any other neurological problems, demonstrate motor proficiency in very low levels. DCD is only related to certain motor skills impairment and not related to intellectual and physical problems like cerebral palsy, pervasive developmental disorder etc. Usually many children are undiagnosed and untreated which causes interference in the academic performance of the child and day to day activities and they appear to be lazy and unmotivated even in playground (4). DCD is usually not diagnosed early because the problem of the child is not considered as a serious problem to make any intervention. This causes the DCD child to suffer from various risk factors that make the person socially and economically different from the surrounding and it paves a way for poor physical health status (5). This makes the child feel inferior in comparison with their peers. These consequences of DCD usually have a long-term impact in life and this causes minimised level of participation in the own care (6). It affects the childhood population of about $1.8 \%-4.8 \%$ with male female ratio of $2: 1$. Cardio respiratory fitness plays a major role in the physical fitness because during physical activity and sustained works CARDIO RESPIRATORY FITNESS is essential for circulatory and respiratory systems in 
supplying oxygen that is the energy fuel (7). The Cardio respiratory fitness is usually a measure of maximum uptake of oxygen by the body (VO2max), i.e. the body's maximum capacity to transport fuel, oxygen and using it during the process of physical activity $(8,9)$. Basically the Cardio respiratory fitness is considered by two major components, one is based on the body's ability to transport oxygen to the muscles when there is a demand in muscles due to increased and sustained physical activity, and the other is the ability of the muscles to absorb and use the oxygen necessary for it (10). But this whole process requires the combined, complete coordination of vitals like heart, lungs, arteries and veins $(11,12)$.

\section{MATERIALS AND METHODS}

The study was designed as comparative study design; study setting was done at four different schools in Chennai. The number of students screened by (DCDQ0'7) were 750, out of which 14 children were found to be under DCD category, 2 children were dropouts and 12 children were recruited for the study under experimental group and 12 children were randomly selected for the control group, based on inclusion and exclusion criteria. Inclusion criteria included both the gender; children between the age of 7-10 years without any disabilities, impairment, or handicapped. The exclusion criteria included children with lower limb disabilities, cardio vascular diseases, and any other genetic defects. The materials required for the study were "DEVELOPMENTAL COORDINATION DISORDER QUESTIONNAIRE 2007 (DCDQ07)", (Bruinink's- Oseretsky Test-ed 2) BOT-2 Tool, wooden blocks, marker cones, measurement tape, stopwatch, nonslip surface, which were used for $20 \mathrm{~m}$ shuttle run test (13). After obtaining consent and ascent from parents and children according to (INDIAN COUNCIL OF MEDICAL RESEARCH) ICMR guidelines DCD Children were screened using DCD 07 Q, BOT-2 tool and based on the (Diagnostic and Statistical Manual of Mental Disorders, ed-5) DSM 5 Criteria. The DCD 07 is a standard measure to find the child's coordination in normal functional activities. It is a valid and reliable questionnaire and the sensitivity and specificity of the questionnaire for the age group $7-17$ years is $88.5 \%$ and $75.6 \%$ respectively, the scores between 15 to 57 indicated DCD (14). This questionnaire consists of 15 items which is grouped into three different factors that include "control during movements, fine motor and handwriting and general coordination" (15). BOT 2 tool was used to measure fine motor skills and gross motor skills of the children, (Diagnostic and Statistical Manual of Mental Disorders, ed-5) DSM-5 diagnostic criteria was used to make a diagnosis of depression for the children, $20 \mathrm{~m}$ shuttle run test was performed for the subjects and the cardio respiratory fitness was evaluated. Before the test, all children and parents were explained about the test procedure and their vitals were also checked, basic demographic data were also collected (16). The VO2 max was calculated post-test for both the groups. During the test the subjects were asked to run back and forth between the two parallel lines as soon as possible by the subject. The setup was made using 2 lines of cones which were placed at the start and end point 30 feet apart. The Children started from the point and ran to the other and picked up the wooden block and got back to the starting point and then continued for the second block and continued the same procedure. Two or three trials were performed and the quickest time in comparison was recorded (17). All data were kept confidential. The cardio respiratory fitness of children with and without DCD was compared and statistical analysis was done.

Ethical Clearance was obtained from IECInstitutional Ethical Committee- Saveetha University.

\section{RESULTS}

From the statistical analysis, it has been revealed that there is a significant difference in cardio respiratory fitness of children with and without DCD. The shuttle run test for the normal children had a mean value of 43.508, with a standard deviation of 5.199 and for the children with DCD the mean value was found to be 37.5083, and the standard deviation is 3.7005 respectively.

Table 1: VO2 max values from shuttle run test

\begin{tabular}{|c|c|c|c|}
\hline $\begin{array}{c}\text { Shuttle } \\
\text { run test }\end{array}$ & Mean & $\begin{array}{c}\text { Standard } \\
\text { deviation }\end{array}$ & $\begin{array}{c}\text { P- } \\
\text { Value }\end{array}$ \\
\hline $\begin{array}{c}\text { Children } \\
\text { without } \\
\text { DCD }\end{array}$ & 43.508 & 5.199 & \multirow{2}{P}{$<0.001$} \\
\hline $\begin{array}{c}\text { Children } \\
\text { with DCD }\end{array}$ & 37.508 & 3.7005 & \\
\hline
\end{tabular}

The data from the above table shows the mean and standard deviation values of $\mathrm{VO} 2$ max from $20 \mathrm{~m}$ shuttle run test. The mean value of children without DCD is 43.508 (SD is 5.199) and for children with DCD is 37.508 ( $S D$ is 3.7005$)$ with $p$ value $(<0.001)$, which is statistically significant. 


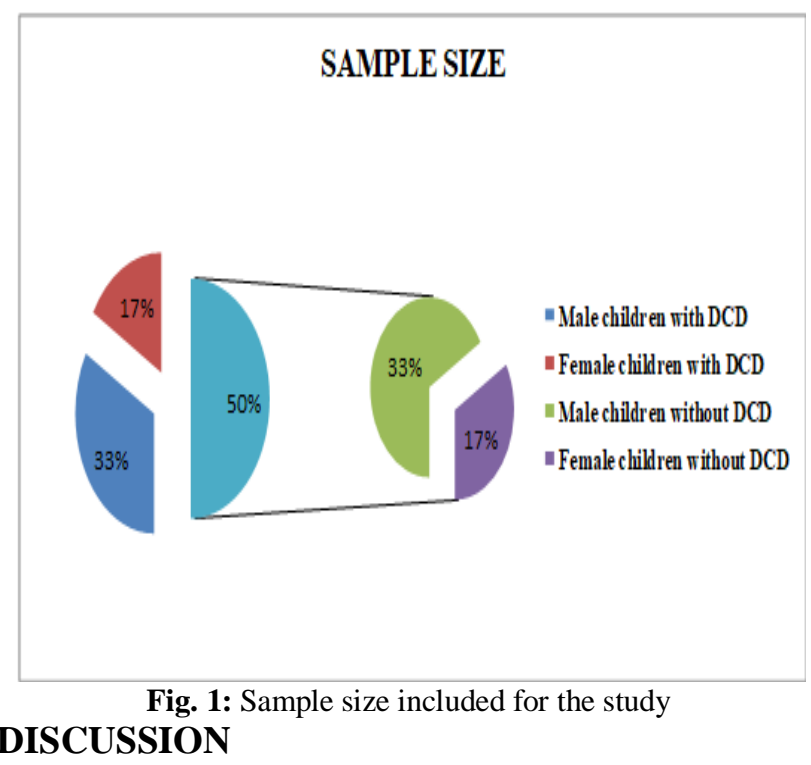

There are many discussions and controversial arguments on cardio respiratory fitness in children with DCD. DCD children who are performing the Legér 20-m shuttle run test or while they run for 6 minutes, they might lead to a disadvantage due to their coordination problems (18). Achenbach in their study concluded that there is a significant mark which shows impairment in motor development that interferes in the day to day functional activities of the children (19). Blishen concluded in 1987 that the motor impairments in DCD children caused difficulties even in speech, language, in reading books (20). It is found that the DCD children often hesitate to participate in sports and in social activities because of the fear due to failure and as a result of minimised physical activities they are found to be obese and this ratio is greater in boys in comparison with girls. Samkar and Saritha in their study have recently screened 50 students, out of which $1.37 \%$ were found to have DCD aged 10years. Cairney et al correlated their study with the previous studies and documented that DCD child will usually have a decreased physical activity and lower fitness levels than their peers (21). This lack of participation leads to a greater gap in fitness and the motor skills between DCD children and normal peers. Hands and Larkin in 2002 came to a decision that it is a cyclic process, which causes the decreased coordination and fitness; decreased participation followed by physical inactivity leading to obesity and further complications and reduced Cardio respiratory fitness (22).

Cairney and Veldhuizen conducted an additional research and suggested that we must obtain more experimental evidences and longitudinal studies to know the accurate relationship between the motor skills, physical inactivity, fitness and obesity (23). However, very less number of researches has been done to examine whether DCD is a risk factor for the low (Cardio respiratory fitness) CRF in children. Though it is expected that the children with DCD will have a low CRF, it might be a direct consequence or any concomitant factor, there are very few evidences for this hypothesis in the literature (24). There are few studies that have examined the relationship between motor problems and CRF in children (25). Future studies are required to prove the importance of improving fitness, and its unique importance in improving the quality of life in these children.

\section{CONCLUSION}

From the results, it has been proved statistically that although both the groups could complete the task, children in the control group completed the task much easier and faster than the children in experimental group. It is found that children with DCD have low Cardio respiratory fitness when compared to children without DCD. The limitation of the current study includes small sample size and minimal duration; thus, it is essential to identify DCD children who are at a greater risk for low Cardio respiratory fitness.

The study, in particular, suggests that poor Cardiorespiratory fitness in these children should be identified early in life or it may lead to development of Cardiovascular diseases in their early adulthood.

Future recommendations include comparison between boys and girls and examining interventions to improve Cardio respiratory fitness in children with DCD and whether such improvements lead to improvement in health-related quality of life for these children.

\section{ACKNOWLEDGMENT}

The authors are grateful to the authorities of school, parents and school teachers who rendered their full support.

\section{CONFLICT OF INTEREST}

Authors declare no conflict of interest.

\section{REFERENCES}

1. Sigmundsson, H., Hansen, P. C., Talcott, J. B. Do clumsy children have visual deficits. Behav Brain Res 2003; 139: 123-129.

2. Harris, Mickelson, Zwicker, 5th ed., DSM-V, American Psychiatric Association, 2013.

3. Smyth, M. M., Mason, U. C. Use of proprioception in normal and clumsy children. Dev Med Child Neurol. 1998; 40: 672-681.

4. Kadesjo, B., Gillberg, C. Developmental coordination disorder in Swedish 7-year-old children. J Am Acad Child Adolesc Psychiatry. 1999; 38: 820-828.

5. Willoughby, C., Polatajko, H. J. Motor problems in children with developmental coordination disorder: review of the literature. Am J OccupTher. 1995; 49: 787-794.

6. Hands, B., Larkin, D. Physical fitness and developmental coordination order. In: Cermak SA, Larkin D (eds). Developmental Coordination Disorder. Delmar: Albany, NY, 2002, pp. 172-184.

7. Welk, G. J., Laurson, K. R., Eisenmann, J. C., Cureton, K. J. Development of youth aerobic-capacity standards using receiver operating characteristic curves. Am J Prev Med 41(4 Suppl 2) 2011: S111-6. 
8. Gordon, R. S., Franklin, K. L, Baker, J. S., Davies, B. Determination of aerobic work and power on a rope-braked cycle ergometer by direct measurement. ApplPhysiolNutrMetab. 2006; 31(4): 392-397.

9. Cantell, M., Crawford, S. G., Doyle-Baker, P. K. Physical fitness and health indices in children, adolescents and adults with high or low motor competence. Hum MovSci 2008; 27(2): 344-362.

10. Li, Y. C., Wu, S. K., Cairney, J., Hsieh, C. Y. Motor coordination and health-related physical fitness of children with developmental coordination disorder: A three-year follow-up study. Res DevDisabil 2011; 32(6): 2993-3002.

11. Fatima, Y.; Doi, S. A. Mamun, A. A. Sleep quality and obesity in young subjects: A meta-analysis. Obes. Rev.2016; 17: 1154-1166. [CrossRef] \{PUBMED\}.

12. Gibbs, J., Appleton, J., Appleton, R. Dyspraxia or developmental coordination disorder? Unraveling the enigma. Arch Dis Child. 2007; 92: 534-539.

13. Aandstad, A., Holme, I., Berntsen, S., Anderssen, S. A Validity and reliability of the 20-meter shuttle run test in military personnel. Military Medicine. 2011; 176: 513-518. [PubMed] [Google Scholar]

14. Agiovlasitis, S., Pitetti, K. H., Guerra, M., Fernhall, B. Prediction of $\mathrm{VO}_{2}$ peak from the 20-m shuttle-run test in youth with Down syndrome. Adapted Physical Activity Quarterly. 2011; 28: 146-156. [PubMed] [Google Scholar]

15. Missiuna, C., Moll, S., King, S., King, G., Law, M. A trajectory of troubles. Physical \& Occupational Therapy in Pediatrics. 2007 January; 27(1): 81-101. [PubMed] [Google Scholar]

16. Rivilis, I., Hay, J., Cairney, J., Klentrou, P., Liu, J., Faught, B. E. Physical activity and fitness in children with developmental coordination disorder: A systematic review. Res DevDisabil. 2011 June; 32(3): 894-910. 10.1016/j.ridd.2011.01.017 [PubMed] [CrossRef] [Google Scholar]

17. Barnett, A., Chan, L. Y. S., Bruce, I. C. A preliminary study of the 20-m multistage shuttle run as a predictor of peak $\mathrm{VO}_{2}$ in Hong Kong Chinese students. Pediatric Exercise Science. 1993; 5: 42-50. [Google Scholar]

18. Cairney, J., Hay, J., Veldhuizen, S., Faught, B. Comparison of $\mathrm{VO} 2$ maximum obtained from $20 \mathrm{~m}$ shuttle run and cycle ergometer in children with and without developmental coordination disorder. Res DevDisabil. 2010; 31(6): 1332-9.

19. Blishen, B. R., Carroll, W. K., Moore, C. The 1981 socioeconomic index for occupations in Canada. Canadian Review of Sociology and Anthropology. 1987; 24: 465-488.

20. Deconinck, F. J., De Clercq, D., Savelsbergh, G. J., Van Coster, R., Oostra, A., Dewitte, G., et al. Differences in gait between children with and without developmental coordination disorder. Motor control. 2006 Apr 1; 10(2): $125-42$.

21. Hands, B., Larkin, D. Physical fitness differences in children with and without motor learning difficulties. Eur J Spec Needs Educ. 2006; 21: 447-56.

22. Kadesjo, B., C. Gillberg. Developmental coordination disorder in Swedish 7-yearold children. J. Am. Acad. Child Adolesc. Psychiatry. 1999; 38: 820-828.

23. Shephard, R. J. Physical Activity and Growth. Chicago, IL: Year Book Medical Publishers, 1982.

24. Allor, K. M., J. M. Pivarnik. Stability and convergent validity of three physical activity assessments. Med. Sci. Sports Exerc. 2001; 33: 671-676,

25. Hands, B., D. Larkin. DCD and physical fitness. In: Developmental Coordination Disorder. S. Cermak and D. Larkin (Eds.). San Diego, CA: Singular Press, 2002. 